\title{
Aqueous extract of Pituranthos scoparius as a biopreservative against lipid oxidation of an emulsion and use of SDS- PAGE to study protein-polyphenols interactions
}

\author{
Anis Chikhoune ${ }^{1 *}$, Mitja Križman ${ }^{2}$, Zahra Berroua ${ }^{3}$, Kaissa Chebbi ${ }^{3}$, Brahim Zeroual ${ }^{4}$, Khellaf Aliane $^{4}$, Samir Hadjal ${ }^{4}$, Abderrahmane \\ Tounsi $^{4}$, Abdelghani Boudjellal ${ }^{1}$ and Mohammed Gagaoua ${ }^{5 *}$ \\ ${ }^{1}$ Equipe Maquav, Laboratoire BIOQUAL, INATAA, Université Frères Mentouri Constantine 1, 7e km Route de Sétif, 25000 Constantine, Algeria \\ ${ }^{2}$ National Institute of Chemistry, Department of Food Chemistry, Hajdrihova 19, SI-1000 Ljubljana, Slovenia \\ ${ }^{3}$ Département des Technologies Alimentaires, INATAA, Université Frères Mentouri Constantine 1, 7e Km Route de Sétif, 25000 Constantine, Algeria \\ ${ }^{4}$ Cévital spa, nouveau quai, port de Bejaia, BP 334, Bejaia 06000, Algeria \\ ${ }^{5}$ Université Clermont Auvergne, INRA, VetAgro Sup, UMR Herbivores, F-63122 Saint-Genès-Champanelle, France
}

\begin{abstract}
In this work, aqueous decoctions with $5 \%$ and $10 \%$ cut and powder plant materials of Pituranthos scoparius were investigated. The best result for the total phenolic extracts was $4.39 \%( \pm 0.05)$ for the $10 \%$ powder plant material extract, whereas the best reducing power was obtained for $5 \%$ powder plant material extract with a mean value of $2.07 \%( \pm 0.06)$. The phytochemical profile of the polyphenol extract was characterized by the presence of chlorogenic acid as a major constituent. Oxidative stability by Rancimat test showed that all the formulations incorporated with the concentrated aqueous extract showed better resistance to oxidation than the control formulation. Moreover, Tricine SDS-PAGE electrophoresis was used to asses protein-polyphenols interactions within the aqueous phase. This efficient technique allowed revealing the formation of a characteristic dimer with molecular weights ranging from 30.3 to $32.4 \mathrm{kDa}$. Densitometric analysis allowed further to highlight the specificy of the interactions within the whey protein at high $(>40 \mathrm{kDa})$ and low molecular weight. The findings of this study, showed that the polyphnolic extract of Pituranthos scoparius offers an attracting alternative for fat products as a natural biopreservative instead of the regular synthetic antioxidants used in food industry.
\end{abstract}

\section{Introduction}

Many natural and processed food products are in an emulsion state, totally or partially, or existed, for a time, in this state [1]. If oil is the dispersed phase and water is the continuous phase, the emulsion is an oil-in-water type or oil-water, whereas if water is the dispersed phase and oil the continuous phase, the emulsion is a water-in-oil type or wateroil [2]. The complex interfacial phenomena taking part in oils and food emulsions makes it difficult to evaluate the efficiency of the antioxidants employed, as the latter is depending on the affinity of antioxidants and their action in the air-oil (bulk oils) and the water-oil (emulsions) interfaces [3]. Therefore, the effectiveness of these antioxidants on lipid peroxidation is intimately depending on the physical state of the substrate (continuous or dispersed phases) [4]. Thereby, in this particular case, the polar paradox is the strongest parameter affecting the efficiency of phenolic antioxidants in a dispersed medium [5].

Whey was traditionally defined as a by-product of cheese-making and considered for years as a waste by the cheese producers, with little or even no commercial value. Nowadays, this idea is totally vanished as whey is gaining greater interest for food technologists. In this context, whey is regarded as an inexpensive source of high nutritional quality protein for uses as a physiologically functional food ingredient. This allows to consider whey as a co-product of cheese-making rather than an abundant by-product of cheese food industries [6,7]. Whey proteins in the group of milk proteins contains numerous protein entities such as $\beta$-Lactoglobulin ( $\beta$-Lg), $\alpha$-Lactalbumin ( $\alpha$-La), serum albumin (SA), Immunoglobulins (Ig), Lactoferrin (LF) and protease-peptone fractions
[8]. A source of about 700,000 tons of whey proteins is available for use as valuable food ingredients, of which about $62 \%$ appears to be gainfully utilized [9]. For example, whey proteins are often used to improve food products because of their high nutritional quality and their versatile functional properties [10].

Pituranthos scoparius is an aromatic widespread plant found mainly in the septentrional Sahara in Algeria and is characterized morphologically by high ramifications for stems. The leaves are almost inexistent and the fruits are very small [11]. It is spelled by the autochthonous people in Algeria by the name of "Guezzah" or "Tataytt" and is traditionally used in treating successfully numerous diseases such as fevers, asthma, hepatitis and rheumatism. Some of the interesting biological activities observed are connected to the presence of alkylated isocoumarins [12].

${ }^{\star}$ Correspondence to: Mohammed Gagaoua, Université Clermont Auvergne, INRA, VetAgro Sup, UMR Herbivores, F-63122 Saint-Genès-Champanelle, France, E-mail: gmber2001@yahoo.fr; mohammed.gagaoua@inra.fr

Anis Chikhoune, Equipe Maquav, Laboratoire BIOQUAL, INATAA, Université Frères Mentouri Constantine 1, 7e km Route de Sétif, 25000 Constantine, Algeria, E-mail: anis.chikhoune@gmail.com; chikhoune.anis@umc.edu.dz

Key words: emulsion, antioxidants, whey proteins, protein-polyphenols interactions, oxidative stability

Received: June 25, 2018; Accepted: July 18, 2018; Published: July 23, 2018 
From what was mentioned above, this study aimed to investigate the oxidative stability of a whey spread emulsion produced at a laboratory scale, incorporated with natural antioxidants from an aqueous extract, obtained by decoction of $P$. scoparius, at concentrations of 100,300 , 600 , and 900 ppm, using a Rancimat test. Furthermore, the interactions between these antioxidants and whey proteins were assessed by the means of Tricine SDS-PAGE followed by Densitometric analysis.

\section{Materials and methods}

\section{Materials}

Refined, bleached and deodorized oils: palm oil (PO), sunflower oil (SFO) and soybean oil (SBO) were obtained from a local refinery (CEVITAL SPA, Bejaia, Algeria). The emulsifier mono lactic acid was purchased from Palsgaard (Denmark) and Anatto Curcumin as a colorant from Global Entreprise (Switzerland). Deionized water, salt and pasteurized milk were from the local rifinery CEVITAL Spa (Bejaia, Algeria).

The pasteurized liquid whey, recovered from a cheese-making process is generously donated by SARL SAFILAI Company (Ali Mendjli, Constantine, Algeria). All these ingredients are of food grade.

The standards of Gallic acid ( $\geq 99 \%$ ), Quercetin $(\geq 98 \%)$ and Ascorbic acid ( $\geq 99 \%)$ were obtained from Sigma-Aldrich (St. Louis, USA). The reagent Folin-Ciocalteu was supplied by Merck (Darmstdat, Germany) and the remaining reagents and solvents were all of analytical grade.

Aerial parts (stems and leaves) of Pituranthos scoparius were collected from the location of Sedrata, Souk Ahras city situated in the Northeast of Algeria. The samples were collected in April 2013. Plant aerial parts were dried at room temperature, a part of the samples was cut into small pieces, and the other dried parts were reduced into powder.

\section{Preparation of the aqueous extracts}

The plant extracts of Pituranthos scoparius were obtained using aqueous decoctions at 5 and $10 \%$. The decoctions were made with two forms of the plant material: plant material cut into small pieces and ground plant material into a fine powder. The use of the cut plant material was guided by the traditional use in folk medicine of the whole plant of Pituranthos in the preparation of the decoctions. Due to its fibrous nature, it was difficult to get a finer powder by simply grinding it with a regular grinder. Therefore, we used a wooden coffee grinder (Alexanderwerk, Germany) to improve the grinding of the plant material. Amounts of $5 \mathrm{~g}$ and $10 \mathrm{~g}$ respectively of the cut and powder materials were prepared in $100 \mathrm{~mL}$ of distilled water, under boiling for $30 \mathrm{~min}$. The extracts were then filtered using a Whatman paper filter and centrifuged at $3000 \mathrm{rpm}$ for $10 \mathrm{~min}$. The supernatants were then stored at $4^{\circ} \mathrm{C}$ until analysis.

\section{Determination of total phenolic content}

The total phenolic contents of the extract were determined according to Gülçın et al. [13], with slight modifications. Briefly, $1 \mathrm{~mL}$ of FolinCiocalteu reagent $(1: 10, \mathrm{v} / \mathrm{v})$ was added to $200 \mu \mathrm{L}$ of each extract. After $3 \mathrm{~min}, 800 \mu \mathrm{L}$ of sodium carbonate solution $(7.5 \% ; \mathrm{m} / \mathrm{v})$ was added. The tubes were placed in darkness for $30 \mathrm{~min}$ and the absorbance was recorded at $725 \mathrm{~nm}$ against a blank. The results were expressed in $\mathrm{g}$ of Gallic Acid Equivalents (GAE) per $100 \mathrm{~g}$ dry weight (DW).

\section{Estimation of flavonoid content}

The flavonoid content was determined according to Djeridane et al. [14], with slight modifications. Briefly, $1 \mathrm{~mL}$ of each sample extract was mixed with $1 \mathrm{~mL}$ of $2 \%$ aluminum chloride solution. After incubation at room temperature for $15 \mathrm{~min}$, the absorbance of the reaction mixture was measured at $430 \mathrm{~nm}$ and the flavonoid content was expressed in $\mathrm{g}$ Quercetine Equivalents (QE) per $100 \mathrm{~g}$ dry weight (DW).

\section{Antioxidant activity by the reducing power}

The method described by Gülçın et al. [13] was used to determine the reducing power of the extracts. An approximate of $200 \mu \mathrm{L}$ of the extract samples were mixed with sodium phosphate buffer ( $\mathrm{pH}$ 6.6, 0.2 $\mathrm{M})$ and potassium ferricyanide $(1 \%, \mathrm{w} / \mathrm{v})$. The mixture was incubated at $50^{\circ} \mathrm{C}$ for $20 \mathrm{~min}$, and $250 \mu \mathrm{L}$ of trichloroacetic acid $(10 \%$, w/v) was added together with distilled water $(1.0 \mathrm{~mL})$ and $200 \mu \mathrm{L}$ ferric chloride $(0.1 \%, \mathrm{w} / \mathrm{v})$. The absorbance was measured at $700 \mathrm{~nm}$ using ascorbic acid as a standard, and the results were expressed as ascorbic acid equivalents (AAE) per $100 \mathrm{~g}$ dry weight (DW).

\section{HPLC-DAD-ESI-MS analysis of the phenolic compounds}

The extract showing the best reducing power, namely the 5\% powder plant material obtained by aqueous decoction was selected for the incorporation in the whey spread emulsion. Before this, it was first characterized for its phenolic compounds. The analysis was performed using a Thermo Accela 600 HPLC system loading an autosampler/injector, vacuum degasser, quaternary pump and coupled to a photodiode array UV-VIS detector (PDA) and a Thermo triple quadrupole (TSQ) mass spectrometer with electrospray ionization (ESI) source operating in negative ionization mode (Thermo Electron Corporation, San Jose, CA, USA).

The Chromatographic separation of metabolites was achieved through a $50 \mathrm{~mm} \times 2.1$ i.d. $\mathrm{mm}, 2.6 \mu \mathrm{m}$ paricle size Kinetex XB-C18 column from Phenomenex (Phenomenex Inc. Torrance, CA, USA). The separation conditions were as follow: mobile phase A, water with $0.1 \%$ FA; mobile phase B, ACN with $0.1 \%$ FA. The elution gradient in $\% \mathrm{~B}$ started at $5 \%$, increased at $20 \%$ in $20 \mathrm{~min}$, raised at $30 \%$ at 20.1 min and kept for 5 and 6 min for column cleaning and equilibration, respectively. Column temperature, flow-rate and injection volume were $22{ }^{\circ} \mathrm{C}, 300 \mu \mathrm{L} \cdot \mathrm{min}^{-1}$ and $5 \mu \mathrm{L}$, respectively. Quantitative UV-Vis detection was performed at $330 \mathrm{~nm}$ and qualitative MS analysis was featured in the $\mathrm{m} / \mathrm{z}$ range of $340-650$ considering multiple reaction monitoring (MRM) transitions detailed by [15]. The analytical device was controlled by a PC loading by the means of Thermo Xcalibur v. 2.1.0 software, which was also used for data processing.

\section{Tricine SDS-PAGE analysis of whey proteins and protein- polyphenols interactions}

For protein-polyphenols interactions study and the assessment of quality of the proteins of the recovered whey, the protocol recently described by our group [16,17] and based on Tricine SDS-PAGE technique, was exactly used.

\section{Preparation of the whey spread emulsion incorporated with the antioxidant aqueous extract of $P$. scoparius}

Emulsions were prepared at a laboratory scale, following the same preparation procedure reported in our earlier work [18]. The aqueous extract of $5 \%$ powder plant material, exhibiting the best reducing power was selected for its incorporation in the emulsions. Thus, the 
Chikhoune A (2018) Aqueous extract of Pituranthos scoparius as a biopreservative against lipid oxidation of an emulsion and use of SDS-PAGE to study proteinpolyphenols interactions

extract was first concentrated by evaporation in a rotavapor (Heidolph, Germany) at $40^{\circ} \mathrm{C}$, prior its incorporation at concentrations of 100,300 , 600, and $900 \mathrm{ppm}$.

\section{Oxidative stability}

The oxidative stability was assessed according to the ISO 6886 standard and our recently described procedure [18].

\section{Statistical analysis}

Data of spectrophotometry are means \pm SD of three measurements. Results of HPLC-MS determinations are means \pm SD of five measurements. Results of Rancimat are means $\pm S D$ of two measurements. Differences between groups were tested by variance analysis (ANOVA) using STATISTICA software (7.0) and values were considered significant at $P$-values $\leq 0.05$.

\section{Results and discussion}

\section{Total phenolics, flavonoids and antioxidant activity of $\boldsymbol{P}$.} scoparius extracts

The total phenolic content, flavonoid content and reducing power of aqueous extracts, obtained from decoctions of cut plant material and powder plant material at respectively 5 and $10 \%$, are given in Table 1 . As expected, the amount of the plant material and the cut or powder forms had significant effects on the total phenolic content $(P \leq 0.05)$. The highest content of total phenolics was obtained for the $10 \%$ aqueous extract of the powdered material (4.39\%) and the lowest content for the $5 \%$ cut plant material (1.64\%). The increase of the amount of the powder plant material allowed to get a higher content for phenolics $(P$ $\leq 0.05)$. On another hand, the highest flavonoid content was obtained for the 5\% cut plant material $(2.03 \%)$ whereas the lowest content was obtained for the powder plant material $(0.90 \%)(P \leq 0.05)$. It is worth to note that the increase of the amount of the powder plant material did not increase the flavonoid content, as it was observed in the case of total phenolics (Table 1).

The reducing power of the extracts of $P$. scoparius are depicted in Table 1 . The findings showed that the reducing power of the aqueous extracts were affected by the amount and form of the plant material $(P \leq 0.05)$. The highest value was obtained for the $5 \%$ powder plant material $(2.07 \%)$ and the lowest content was obtained for the $10 \%$ cut plant material $(0.50 \%)(P \leq 0.05)$.

\section{Phytochemical profile of the extract by HPLC-DAD-ESI-MS analysis}

The qualitative and quantitative phytochemical profile was carried out on the previously selected extract of P. scoparius (to be incorporated

Table 1. Total phenolic (TPC), total flavonoid (TFC) contents and reducing power (RP) of the aqueous decoctions of $P$. scoparius studied

\begin{tabular}{|c|c|c|c|}
\hline Plant material & TPC $^{\mathbf{1}}$ & TFC $^{\mathbf{2}}$ & RP $^{\mathbf{3}}$ \\
\hline Powder plant material 5\% & $2.41 \pm 0.12^{\mathrm{c}}$ & $1.04 \pm 0.06^{\mathrm{b}}$ & $2.07 \pm 0.04^{\mathrm{a}}$ \\
\hline Powder plant material 10\% & $4.39 \pm 0.05^{\mathrm{a}}$ & $0.90 \pm 0.01^{\mathrm{b}}$ & $1.74 \pm 0.02^{\mathrm{b}}$ \\
\hline Cut plant material 5\% & $1.64 \pm 0.09^{\mathrm{d}}$ & $1.20 \pm 0.03^{\mathrm{b}}$ & $0.85 \pm 0.02^{\mathrm{c}}$ \\
\hline Cut plant material 10\% & $2.95 \pm 0.04^{\mathrm{b}}$ & $2.03 \pm 0.33^{\mathrm{a}}$ & $0.50 \pm 0.01^{\mathrm{d}}$ \\
\hline
\end{tabular}

Means not sharing the same letter in the same column are significantly different $(P \leq 0.05)$.

${ }^{1}$ Total phenolic contents are expressed as gallic acid equivalents; grams of gallic acid per $100 \mathrm{~g}$ of dry weight ( $\mathrm{g}$ GAE/100 $\mathrm{g}$ dry weight).

${ }^{2}$ Total Flavonoid contents are expressed as quercetin equivalents; grams of quercetin per $100 \mathrm{~g}$ of dry weight (g QE/100 g dry weight).

${ }^{3}$ Reducing power expressed as ascorbic acid equivalents; grams of ascorbic acid per $100 \mathrm{~g}$ of dry weight (g AAE/100 g dry weight).
Table 2. Phenolic compounds identified in the aqueous extract of $P$. scoparius

\begin{tabular}{|c|c|c|}
\hline Compound & MS parent ion (m/z) & Aqueous extract $^{1}$ \\
\hline 3-O-Caffeoylquinic acid & 353 & $15.44 \pm 0.14^{\mathrm{e}}$ \\
\hline 5-O-Caffeoylquinic acid & 353 & $470.1 \pm 4.37^{\mathrm{a}}$ \\
\hline 4-O-Caffeoylquinic acid & 353 & $16.56 \pm 0.15^{\mathrm{e}}$ \\
\hline Unknown peak & 367 & $69.01 \pm 0.64^{\mathrm{c}}$ \\
\hline Quercetin-3-O-rutinoside & 609 & $74.83 \pm 0.70^{\mathrm{b}}$ \\
\hline Quercetin-3-Oglucuronide & 477 & $70.91 \pm 0.66^{\mathrm{c}}$ \\
\hline Unknown peak & 491 & $23.02 \pm 0.21^{\mathrm{d}}$ \\
\hline
\end{tabular}

Means sharing the same letters in the column are not significantly different $(P \leq 0.05)$.

${ }^{1}$ The values are the mean \pm standard deviation of 5 replicates and expressed as $\mathrm{mg}$ equivalents of chlorogenic acid/100g dry weight.

in the emulsion). The results of the HPLC-DAD-ESI-MS system are depicted in Table 2 showing different separated and identified constituents, with known and unknown peaks. The compound identified as 5-O-Caffeoylquinic acid (chlorogenic acid) is by far the major compound in the extract, depicting the highest content $(470.13$ mg CAE. $100 \mathrm{~g}^{-1}$ dry weight $)(P \leq 0.05)$. The two other phenolic acids, 3-O-Caffeoylquinic and 4-O-Caffeoylquinic, were the less abundant compounds in the extract compared to chlorogenic acid $(P \leq 0.05)$. Flavonoids are also present and were identified as Quercetin-3-Orutinoside and Quercetin-3-Oglucuronide, respectively. Their contents are lower than chlorogenic acid by an order of magnitude of $6(P \leq$ 0.05). The contents of the present work are much higher than those reported by Dahia et al. [19]. Indeed, the authors reported also a higher content of chlorogenic acid compared to the rest of constituents mainly represented by flavonoids.

From these findings, it can be emphasized that a chromatographic method is suitable for the extracts of $P$. scoparius to shed light on the other compounds present in the extract. Being a simple polyphenolic ester antioxidant and highly bioavailable, chlorogenic acid is recognized as an effective and protective agent in animals against some neurodegenerative diseases [20]. Moreover, its high antioxidant potential is more accessible than many of the flavonoids known as effective radical scavengers [21].

\section{Oxidative stability by the Rancimat methods}

The induction periods (IP) of the whey spread emulsions added by the concentrated aqueous extract of $5 \%$ cut plant material for every concentration of incorporation used $(100,300,600$, and 900 ppm) as assessed by the Rancimat test were listed in Table 3. The aqueous extract was found to be more effective in stabilizing the emulsion against oxidative deterioration, compared to the control emulsion containing $\alpha$-Tocopherol as antioxidant. All the concentrations studied exhibited higher IP than the control $(P \leq 0.05)$ with an average of 14.40 $\mathrm{h}$. For a concentration of $300 \mathrm{ppm}$, the emulsion gave an IP of $16.53 \mathrm{~h}$, higher than all the other concentrations $(P \leq 0.05)$. These findings are in agreement with those reported previously by our group [18], using the essential oil of $P$. scoparius as a food preservative. A similar study conducted to investigate the protective effect of three aromatic herbs on the oxidative stability of an oil-in-water emulsion demonstrated the antioxidant properties of the herbs studied and their positive effect in delaying oxidation. Hence, they can be considered as natural antioxidant green alternatives to synthetic antioxidants in food preservation [22].

According to an earlier study, Rancimat method allows the prediction of sunflower oil's shelf life incorporated by a polyphenolic extract from sage, based on the assessement of the oxidative stability induced in the fat matrix [23]. The concentrations of the sage extract (1200 and $1500 \mathrm{ppm}$ ) provinding a protective effect on oxidation 
Table 3. Parameters of the oxidative stability of the whey spread emulsion incorporated with different concentrations of the aqueous extract of $P$. scoparius

\begin{tabular}{|c|c|c|}
\hline Antioxidant & Concentration ( $\left.\mathrm{mg} \mathrm{kg}^{-1}\right)$ & Induction period (hours) ${ }^{1}$ \\
\hline $\mathrm{WSE}^{*}+\alpha$-Tocopherol & 100 & $14.40 \pm 0.02^{\mathrm{e}}$ \\
\hline WSE+AEPS** & 100 & $16.31 \pm 0.03^{b}$ \\
\hline WSE+AEPS & 300 & $16.53 \pm 0.04^{\mathrm{a}}$ \\
\hline WSE+AEPS & 600 & $14.93 \pm 0.04^{\mathrm{d}}$ \\
\hline WSE+AEPS & 900 & $15.60 \pm 0.03^{\mathrm{c}}$ \\
\hline \multicolumn{3}{|c|}{$\begin{array}{l}{ }^{1} \text { Means not sharing the same letter in the column are significantly different }(P \leq 0.05) \text {. } \\
\text { "WSE: Whey Spread Emulsion } \\
{ }^{* *} \text { Whey Spread Emulsion incorporated with the concentrated aqueous extract from the } 5 \% \\
\text { powdered plant material of } P \text {. scoparius }\end{array}$} \\
\hline
\end{tabular}

were, however, greater than those used in this study. Also, the use of polyphenolic extracts of plants and commercial teas in unstripped sunflower oils and mayonnaise samples could minimize lipid oxidation thanks to their antioxidants content and therefore enhance the oxidative stability of the lipid test systems studied [24]. The substitution of synthetic antioxidants with natural ones is suggested to be a good strategy to conteract the adverse effects of the latters, in terms of high concentrations use and low thermal stability observed during heat processing and frying of food products. Overall, natural antioxidants present the benefits to be recovered from low cost resources, with higher antioxidant activity and thermal stability than their synthetic conterparts [25]

\section{Whey protein-polyphenols interaction by SDS-PAGE}

Being motivated by the results obtained by our recent study on the interactions of antioxidants recovered from Hibiscus sabdariffa with whey proteins in a whey spread emulsion [16], we conducted this study to confirm those statements and to study the interactions of the antioxidants recovered from $P$. scoparius with proteins from the aqueous phase of a whey spread emulsion. Thus, the wehy spread emulsion containing the lowest amount of the aqueous extract $(100 \mathrm{ppm})$ has been selected to the study of protein-polyphenols interactions.

The Tricine SDS-PAGE patterns showed in Figure 1, depict blank whey proteins after pasteurization at $70{ }^{\circ} \mathrm{C}$ during $20 \mathrm{~min}$ (lane 1), the aqueous phase recovered from whey spread emulsion obtained by phase separation (lane 2), pure $\beta$-Lactoglobulin ( $\beta$-Lg) (lane 3) and pure Bovin Serum Albumin (BSA) (lane 4). When visualizing the gel, the characteristic and different protein bands were easily recognizable. Lane 1 depicted very strong intensity of protein bands, with molecular weights respectively around $14 \mathrm{kDa}$ and $18 \mathrm{kDa}$, and a very weak band intensity around $70 \mathrm{kDa}$. These bands corresponds respectively to $\alpha$-Lactalbumine ( $\alpha$-La), $\beta$-Lg and BSA, as confirmed by pure standard of these proteins which were loaded in the lanes 3 and 4 , respectively. Lane 2 clearly showed the formation of a dimer with a high molecular weight $(30 \leq \mathrm{MW} \leq 32 \mathrm{kDa})$. This high molecular complex formed did not undergo any split even with the presence of SDS and $\beta$-mercaptoethanol, likely to the strong association between the major whey proteins and some phenolic compounds present in the aqueous phase. Previous studies reported that the bonds involved are likely to be of covalent nature, with enhancement of intermolecular cross-linking $[26,27]$. The main protein involved in this case is $\beta-\mathrm{Lg}$. Indeed, a study by Rawel et al. suggested the occurrence of a likely covalent cross linking, as a direct consequence of reactions at the free amino groups and tryptophan, so that $o$ - or $p$-diphenols are oxidized to quinones, which react with lysine and tryptophan side chains in proteins [26]. However, this study showed a very good and interesting oxidative stability of the whey spread emulsion incorporated with aqueous extract of $P$. scoparius via the Rancimat method. Although the formation of a whey protein-polyphenols complex, antioxidants still protect the emulsion from oxidation. Accordingly, Almajano et al. reported that an adduct is formed by the whey protein-phenolic acids complex, but the antioxidant activity of the phenolic acids involved is still intact [28].

In order to confirm whether the dimer observed in the aqueous phase is a complex formed due to polyphenol-whey protein interactions, a Tricine SDS-PAGE analysis was carried out on a mix of whey proteins/

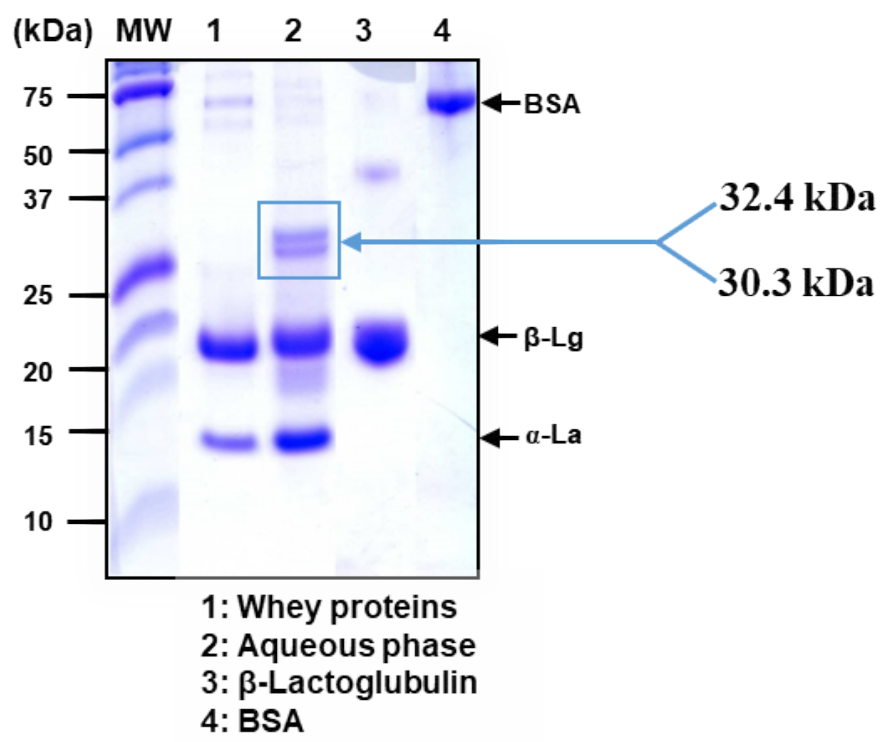

Figure 1. SDS-PAGE analysis depicting the Coomassie blue gel of whey proteinpolyphenols complexes of $P$. scoparius occurring in the aqueous phase of the whey spread emulsion. Lanes: (MW) standard protein marker (given in $\mathrm{kDa}$ at left-hand side); (1): crude whey; (2): Aqueous phase recovered from the whey spread emulsion; (3): pure $\beta$-lactoglobulin standard $(4 \mu \mathrm{g})$; (4): pure Bovine Serum Albumin (BSA) standard. The molecular weight of the framed protein dimers (whey protein-polyphenols complex) were determined by densitometry
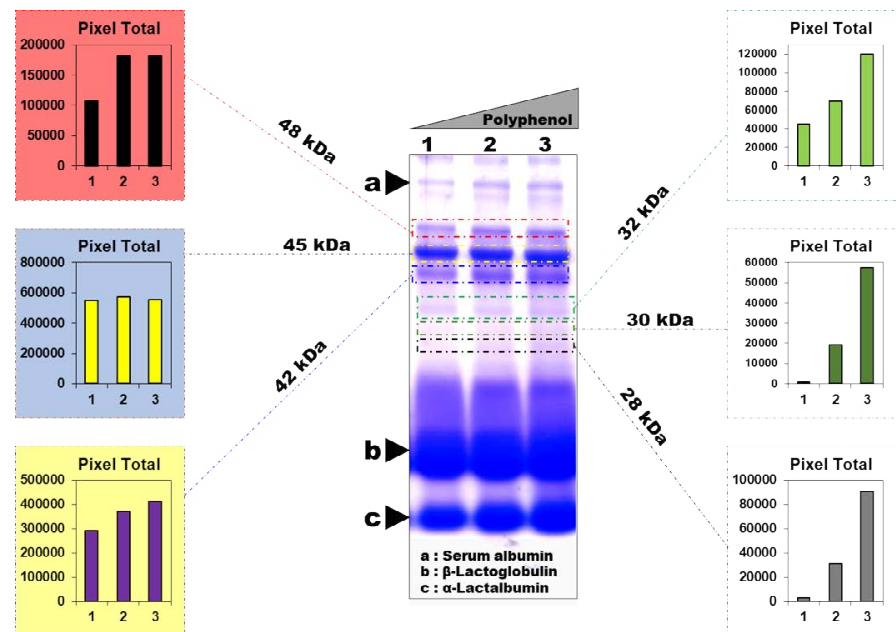

Figure 2. SDS-PAGE and densitometry analyses of whey protein-polyphenols complexes of $P$. scoparius. The experiment was performed using a mix of antioxidants and whey by a direct contact of the concentrated aqueous extract with liquid whey used in the whey spread emulsion, at different ratios (gradient) of liquid whey/aqueous extract $(1: 75 ; 1: 150$ and 1:175). The arrows highlight a) Bovine Serum Albumin (BSA); b) $\beta$-Lactoglobulin ( $\beta$-Lg) and c) $\alpha$-Lactalbumin $(\alpha$-La). Each protein band at each concentration of the antioxidant is given at left (protein bands with $\mathrm{MW}>40 \mathrm{kDa}$ ) and right (protein bands with $\mathrm{MW} \leq 32$ $\mathrm{kDa}$ ) of the Coomassie blue gel with the corresponding total pixel intensities obtained by the means of densitometry analysis conducted by Un-Scan-It gel 6.1 analysis program (Silk Scientific, Orem, UT) 
antioxidants of different ratios; for instance 1:75, 1:150 and 1:175 (v/v), respectively. As depicted in Figure 2, densitometric analysis performed on the different protein bands of the gel highlighted the presence of band intensities corresponding to several complexes with different molecular weights. From the visualized Coomassie blue bands, 6 complexes were observed and at different molecular weights : $28,30,32$, 42,45 , and $48 \mathrm{kDa}$. The results showed that the formation of the band depends on the molecular weight of the complex formed, and likely to that of the involved protein. On the basis of the histograms presented, the tendency of band intensities is mass-dependant for the complexes formed. Indeed, the increase of band intensities was strongly related with increasing amounts of whey proteins for low molecular weights $(28,30$, and $32 \mathrm{kDa})$. As previously reported, the dimer formed showed two intense bands of 30.3 and $32.4 \mathrm{kDa}$, respectively. As the amount of the whey proteins fraction is relatively high $(10 \mu \mathrm{g}$ or $20 \mu \mathrm{L})$ in the mixes of different ratios, a broadening effect was noticed for the proteins $\beta$ - $\mathrm{Lg}$ and $\alpha-\mathrm{La}$ (major proteins in whey). Likely, there is no specific binding of these polyphenols on the surface of whey proteins. Their adsorption was not specifically occurring and the whole polyphenol is stacked onto each whey protein, irrespective of their chemical nature [29]. Therefore, it can be assumed that many polyphenols can bind at multiple sites on peptides as already reported [30]. On the contrary, for the complexes 42,45 , and $48 \mathrm{kDa}$, thus all protein with molecular wieght $>40 \mathrm{kDa}$, the tendency is totally different and no general rule can be drawn from the evolution of band intensities and the molecular weights. However, further studies using accurate tools, such mass spectrometry to identify the origin and the relationships are required. The highly specific interactions suggest that the differences in affinity are functionally significant if we refer to some previous studies [31]. Moreover, it is worthwhile to cite that the strength of interactions depends on size of polyphenols, polyphenol structure and amino-acid protein sequence [32]. The polyphenolic compound may be also preserved in the complex formed and a positive effect would be in this situation related to the complexation phenomena since the overall antioxidant activity of the polyphenols is preserved [33].

\section{Conclusion}

From the findings of the present study, we can conclude that $P$. scoparius is a potential source of bioactive compounds that exert a protective effect against oxidation. This is particularly important for food preservation, aiming to substitute sythetic antioxidants by natural ones, easily recoverable from available plant materials using relatively low cost processes. The evaluation of the polyphenolic content via spectrophotometry and their separation, quantification and identification via HPLC-DAD-ESI-MS revealed the occurrence of these antioxidants, among which chlorogenic acid, recognized to be even more effective than other flavonoids detected (quercetin) in delaying the oxidation process in whey spread emulsions. The results of Rancimat supported the beneficial effect of the aqueous extract as a natural additive. The aqueous phase showed the occurrence of a protein dimer, revealed by Tricine SDS-PAGE, resulting from the interactions between polyphenols of the aqueous extract and the whey proteins in the aqueous phase recovered from the whey spread emulsion. The dimer is a complex of molecular weight ranging from 30.3 to 32.4. Further works are still to be done under a double scope: $i$ ) identification of molecules involved in the complexation reaction between polyphenols and whey proteins, and to understand the underlying mechanisms by which they interact and more likely to propose a general scheme of interactions in real food formulations. $i$ ) a scale up and a valorization of the industrial application of these natural extracts in the fat and oils industry. Finally, we intend to propose in the forthcoming future versatile mixtures of several antioxidant components easy and ready-to-use as natural additives for manufacturers and customers of miscellaneous agro-food industries.

\section{Acknowledgements}

The authors deeply thank the staff of CEVITAL spa. company at Bejaia city for their support and assistance. We further convey special thanks to Mr. Boualem HADJADJ and Mrs Amel SEFARI for their constant support and valuable help. The authors thank also INATAA, Université Frères Mentouri Constantine 1 for the financial support given to the research activities of A.C. Authors are also grateful for the financial support from the Slovenian Research Agency (P1-0005) and their valuable contribution. Authors would like to dedicate this work to Pr. Dr. LOUAILECHE H., full professor in the department of Food Sciences, FSNV, Université Abderrahmane Mira de Béjaia, in loving memory of the one who gave her soul to science with so much devotion and passion. You will never be forgotten.

\section{Conflict of interest}

The authors declare that there is no conflict to disclose.

\section{References}

1. Di Mattia CD, Sacchetti G, Pittia P (2011) Interfacial Behavior and Antioxidant Efficiency of Olive Phenolic Compounds in O/W Olive oil Emulsions as Affected by Surface Active Agent Type. Food Biophysics 6: 295-302.

2. Phillips L, Whitehead D, Kinsella J (1994) Structure-function properties of food proteins. Academic Press San Diego.

3. Frankel EN, Huang SW, Kanner J, German JB (1994) Interfacial phenomena in the evaluation of antioxidants: bulk oils vs emulsions. J Agric Food Chem 42: 1054-1059.

4. Bondet V, Cuvelier ME, Berset C (2000) Behavior of phenolic antioxidants in a partitioned medium: Focus on linoleic acid peroxidation induced by iron/ascorbic acid system. J Amer Oil Chem Soc 77: 813.

5. Cuvelier ME, Bondet V, Berset C (2000) Behavior of phenolic antioxidants in a partitioned medium: structure-Activity relationship. J Amer Oil Chem Soc 77: 819-824.

6. Walzem R, Dillard C, German JB (2002) Whey components: millennia of evolution create functionalities for mammalian nutrition: what we know and what we may be overlooking. Crit Rev Food Sci Nutr 42: 353-375. [Crossref]

7. Luhovyy BL, Akhavan T, Anderson GH (2007) Whey proteins in the regulation of food intake and satiety. J Am Coll Nutr 26: 704S-12S. [Crossref]

8. Farrell H, Jimenez-Flores R, Bleck G, Brown E, Butler J, et al. (2004) Nomenclature of the proteins of cows' milk—sixth revision. J Dairy Sci 87: 1641-1674.

9. de Wit JN (1998) Marschall Rhône-Poulenc Award Lecture. Nutritional and functiona characteristics of whey proteins in food products. J Dairy Sci 81: 597-608. [Crossref]

10. De Wit J (1990) Thermal stability and functionality of whey proteins. J Dairy Sci 73 3602-3612

11. Belgacem D, Ali K, Rachid R, Djazia A (2016) Effect of Pituranthos scoparius essential oils on reducing methanogenesis in cheep: In Vitro study. Environmental Science: An Indian Journal 12: 118-126.

12. Hamada H, Mohammed B, Massiot G, Long C, Lavaud C (2004) Alkylated isocoumarins from Pituranthos scoparius. Nat Prod Res 18: 409-413.

13. Gülçın İ, Oktay M, Kıreçcı E, Küfrevığlu Öİ (2003) Screening of antioxidant and antimicrobial activities of anise (Pimpinella anisum L.) seed extracts. Food Chem 83: 371-382.

14. Djeridane A, Yousfi M, Nadjemi B, Boutassouna D, Stocker P, et al. (2006) Antioxidant activity of some Algerian medicinal plants extracts containing phenolic compounds. Food Chem 97: 654-660.

15. Križman M, Baričevič D, Prošek M (2007) Determination of phenolic compounds in fennel by HPLC and HPLC-MS using a monolithic reversed-phase column. J Pharm Biomed Anal 43: 481-485. [Crossref] 
Chikhoune A (2018) Aqueous extract of Pituranthos scoparius as a biopreservative against lipid oxidation of an emulsion and use of SDS-PAGE to study proteinpolyphenols interactions

16. Chikhoune A, Gagaoua M, Nanema KD, Souleymane AS, Hafid K, et al. (2017) Antioxidant Activity of Hibiscus sabdariffa Extracts Incorporated in an Emulsion System Containing Whey Proteins: Oxidative Stability and Polyphenol-Whey Proteins Interactions. Arabian Journal for Science and Engineering 42: 2247-2260.

17. Gagaoua M, Boucherba N, Bouanane-Darenfed A, Ziane F, Nait-Rabah S, et al. (2014) Three-phase partitioning as an efficient method for the purification and recovery of ficin from Mediterranean fig (Ficus carica L.) latex. Sep Purif Technol 132: 461-467.

18. Chikhoune A, Damjan Pavleca J, Shashkov M, Berroua Z, Chebbi K, et al. (2017) Antioxidant effect induced by the essential oil of Pituranthos scoparius in a formulation of a whey spread emulsion. J Food Process Preserv 41: e13163.

19. Dahia M, Siracusa L, Laouer H, Ruberto G (2009) Constituents of the polar extracts from Algerian Pituranthos scoparius. Nat Prod Commun 4: 1691-1692. [Crossref]

20. Dixon RA (2005) Engineering of plant natural product pathways. Curr Opin Plant Biol 8: 329-336.

21. Niggeweg R, Michael AJ, Martin C (2004) Engineering plants with increased levels of the antioxidant chlorogenic acid. Nat Biotechnol 22: 746-754. [Crossref]

22. Gallego MG, Gordon MH, Segovia FJ, Skowyra M, Almajano MP (2013) Antioxidant properties of three aromatic herbs (rosemary, thyme and lavender) in oil-in-water emulsions. J Amer Oil Chem Soc 90: 1559-1568.

23. Upadhyay R, Mishra HN (2014) Multivariate Analysis for Kinetic Modeling of Oxidative Stability and Shelf Life Estimation of Sunflower Oil Blended with Sage (Salvia officinalis) Extract Under Rancimat Conditions. Food and Bioprocess Technology 8: 801-810.

24. Ramsaha S, Aumjaud BE, Neergheen-Bhujun VS, Bahorun T (2015) Polyphenolic rich traditional plants and teas improve lipid stability in food test systems. J Food Sci Technol 52: 773-782. [Crossref]
25. Taghvaei M, Jafari SM (2015) Application and stability of natural antioxidants in edible oils in order to substitute synthetic additives. J Food Sci Technol 52: 1272-1282. [Crossref]

26. Rawel HM, Kroll J, Hohl UC (2001) Model studies on reactions of plant phenols with whey proteins. Nahrung 45: 72-81. [Crossref]

27. Rawel HM, Czajka D, Rohn S, Kroll J (2002) Interactions of different phenolic acids and flavonoids with soy proteins. Int J Biol Macromol 30: 137-150. [Crossref]

28. Almajano MP, Delgado ME, Gordon MH (2007) Changes in the antioxidant properties of protein solutions in the presence of epigallocatechin gallate. Food Chem 101: 126130

29. von Staszewski M, Jara FL, Ruiz AL, Jagus RJ, Carvalho JE, et al. (2012) Nanocomplex formation between $\beta$-lactoglobulin or caseinomacropeptide and green tea polyphenols: Impact on protein gelation and polyphenols antiproliferative activity. $J$ Funct Foods 4: $800-809$

30. Charlton AJ, Baxter NJ, Khan ML, Moir AJ, Haslam E, et al. (2002) Polyphenol/ peptide binding and precipitation. J Agric Food Chem 50: 1593-1601. [Crossref]

31. Asquith TN, Butler LG (1986) Interactions of condensed tannins with selected proteins. Phytochem 25: 1591-1593.

32. Frazier RA, Deaville ER, Green RJ, Stringano E, Willoughby I, et al. (2010) Interactions of tea tannins and condensed tannins with proteins. J Pharm Biomed Anal 51: 490-495.

33. Stojadinovic M, Radosavljevic J, Ognjenovic J, Vesic J, Prodic I, et al. (2013) Binding affinity between dietary polyphenols and $\beta$-lactoglobulin negatively correlates with the protein susceptibility to digestion and total antioxidant activity of complexes formed. Food Chem 136: 1263-1271. [Crossref]

Copyright: (C2018 Chikhoune A. This is an open-access article distributed under the terms of the Creative Commons Attribution License, which permits unrestricted use, distribution, and reproduction in any medium, provided the original author and source are credited. 